\title{
Cultivating Holistic Health and Wellness among the Adolescent Girls through a Padman-Like Initiative in Chandigarh Schools via an Information Booklet
}

\author{
Risha Gupta', Seema Chopra², Almarjeet Singhr', Z1K Sinha4 \\ ${ }^{1}$ PhD Scholar, ${ }^{3}$ Professor, Department of Community Medicine, PGIMER, Chandigarh. \\ ${ }^{2}$ Associate Professor, Department of Obstetrics \& Gynecology, PGIMER, Chandigarh. \\ ${ }^{4}$ Professor, Department of Anthropology, Panjab University, Chandigarh.
}

DOI: https://doi.org/10.24321/2454.325X.201819

\begin{abstract}
Introduction: Health promotion is the process of enabling people to increase control over their health and its determinants, and thereby improve their health. ${ }^{1}$ Adolescent girls should also be enabled to increase control over their health. We need to mediate on their behalf to ensure easy access to relevant information and care related to health problems of adolescent girls.

Objectives: (1) To ascertain the information needs about puberty-related health problems among the adolescent school-going girls of Chandigarh. (2) To develop, validate and introduce an educational booklet among the adolescent school-going girls addressing their healthcare needs in a holistic way.

Methodology: A preliminary study was conducted from Jan 2015 to May 2015 in four schools of Chandigarh (30 girls from each school). Based on the results of this study, a comprehensive booklet has been developed, validated and published covering all the puberty-related aspects of girls in a holistic way. The booklet will be introduced in 52 schools of UT Chandigarh - 26 government and 26 private schools. 16 schools have been covered till date.

Results: The major problems faced by girls at puberty include irregular menstruation, dysmenorrhea, excess facial hair growth, obesity and acne. The booklet was developed and validated by 10 experts and 14 respondents with validation score ranging from 8 to 10 . The booklet was then introduced among 16 schools and the response was quite good and encouraging. Teachers even asked for extra copies of the booklet and said "Hum library funds utilize karke aur books mangwa lenge".

Conclusion: The girls showed eagerness to know about their health problems. There is a great demand for the information booklet as it seemed to be a handy helpline for girls to solve their many health problems.

Keywords: Adolescent girls, Puberty, Menstruation, PCOS, Self-esteem
\end{abstract}

Corresponding Author: Dr. Risha Gupta, Department of Community Medicine, PGIMER, Chandigarh.

E-mail Id: rishagupta29@gmail.com

Orcid Id: https://orcid.org/0000-0002-9553-3533

How to cite this article: Gupta R, Chopra S, Singh A et al. Cultivating Holistic Health and Wellness among the Adolescent Girls through a Padman-Like Initiative in Chandigarh Schools via an Information Booklet. Int J Preven Curat Comm Med 2018; 4(3): $20-25$. 


\section{Introduction}

Adolescent girls represent one of the most vulnerable sections of the society. They face many health problems at this crucial phase. They have to be fully equipped with the self-management skills to solve their own problems.

Adolescence is considered to be the period between ages 10 and 19. In order to lead healthy, responsible lives and protect themselves from reproductive health problems, adolescents need to be knowledgeable about themselves and need adequate information about the physical and physiological changes that take place during puberty, menstruation and childbirth. In lieu of this, we have developed a comprehensive intervention booklet/ self-instruction manual.

Adolescent girls face many health problems which can be attributed to their faulty lifestyle, viz., obesity, polycystic ovarian syndrome (PCOS), menstrual irregularities, poor scholastic performance, reproductive tract infections, stress, etc. The probability of emergence of these problems can be minimized by adopting a health-promoting approach. Health promotion is the process of enabling people to increase control over their health and its determinants, and thereby improve their health. ${ }^{1}$ We need to mediate on their behalf to ensure easy access to relevant information and care related to health problems of adolescent girls.

This study aims to incorporate self-management skills in the adolescent girls through a comprehensive package, i.e., a self-instruction manual so that they could manage their puberty-related health problems in their own way.

Appropriate knowledge and access to resources are critical to improve reproductive health in a sustainable way. Adolescence is the time to learn and adopt healthy habits to avoid many health problems later in life. Adolescents have more easy access to information through schools, recreational activities, and mass media than they have later in their lives.

With menarche, girls learn to live with various restrictions in their daily lives. In addition to the personal social and health concerns associated with puberty, girls are not yet fully equipped with adaptive skills of problem solving. ${ }^{2}$ Thus, incorporating self-management skills can improve the overall well-being of adolescent girls. This can be done with the help of educational interventions which should include all the necessary information and self-management skills.

School-going age is the best age for introducing any lifestyle intervention, because students not only acquire knowledge but also imbibe values, develop an understanding of social norms that finally influence their behaviors and adoption of healthy practices. Hence, the present study was planned to evolve and pretest various educational strategies to resolve the puberty-related health problems in the school-going adolescent girls in a comprehensive way.

\section{Methodology}

It was a cross-sectional study. In total, 120 girls were selected by simple random sampling technique from four schools of Class IX and X (30 from each school). The information was sought by administering a semi-structured questionnaire. The tool consisted of the questions pertaining to their routine puberty-related health problems with special emphasis on their awareness level and management practices.

Data was collected after taking informed consent from the participants and consent from the respective authorities of the schools. Data collected was analyzed using Epidata and SPSS statistical software.

After ascertaining the information needs of adolescent girls, a booklet was prepared addressing their needs in a comprehensive way. It was prepared on the basis of the results of the above-mentioned study, review of literature, and expert views.

It was then pilot tested among 16 participants/adolescent girls from two schools (8 from each school) of UT Chandigarh. The girls were selected by simple random sampling technique. A criteria rating tool was administered to ascertain the face and content validity of the booklet. Also it got validated from the panel of experts from public health, gynecology, anthropology, dermatology, psychology, etc., fraternities.

After the validation, a randomized controlled trial was planned to ascertain the impact of intervention package on the pattern and prevalence of puberty-related health problems among the adolescent school-going girls of UT Chandigarh. In total, 52 schools will be recruited in the study through cluster randomization (26 in intervention I and 26 in intervention II). Intervention I contains SIM (Selfinstruction Manual) and intervention II contains SIM and live training session. 16 schools from group intervention I have already been covered. This article presents preliminary findings only.

\section{Results}

The mean age of the respondents recruited in the preliminary study was $14.26 \pm 0.76$ years. The results showed that the girls considered menstruation as the most disturbing factor followed by pubic hair and acne. Major source of information about puberty was the mother for most of the girls (80\%), followed by friends and sisters.

Half of the girls reported missed periods for more than three times, but majority were doing nothing to manage 
them. Majority (73\%) of the girls experienced pain during menstruation, out of which $29.5 \%$ girls frequently took leave from school due to this pain. Many (33) girls tolerated their menstrual pain as such. The practice adopted mainly was hot water bottle by 35 girls.

Table 1.The Reason for Tolerating as such the Menstrual Pain by the Respondents $(n=120)$

\begin{tabular}{|c|c|c|}
\hline Reason for Tolerating as such the Pain & Number & $\%$ \\
\hline Not applicable & 83 & 69.16 \\
\hline Shyness to discuss with someone & 6 & 5 \\
\hline Influence of mother/grandmother & 21 & 17.5 \\
\hline Lack of knowledge & 4 & 6.7 \\
\hline Fear of any disease diagnosed & 1 & 1.7 \\
\hline Other & 5 & 8.3 \\
\hline Chi-square test (p-value)** & \multicolumn{2}{|c|}{ to $p=.00000112$} \\
\hline
\end{tabular}

**Statistically significant $\mathrm{p}$-value $<0.05$

The main reason for tolerating as such the pain was influence of mother/grandmother, followed by shyness to discuss with someone.

Only $27.5 \%$ girls' practiced exercises daily like dancing, jogging, jumping, walking, etc., for on an average 30-60 minutes.

Table 2.Various Problems Faced by Girls in Their Appearance (n=120)

\begin{tabular}{|c|c|c|c|}
\hline Problems Faced by Girls & Number & $\%$ & Chi-square Test (p-value) \\
\hline Excess facial hair growth & 17 & 14.16 & .0024 (<0.05 i.e. statistically significant) \\
\cline { 1 - 3 } Acne & 41 & 34.16 & \\
\hline Fatty body & 42 & 35 & \\
\hline
\end{tabular}

Acne and fatty body were the major problems faced by most of the girls.

Based on the information received above, a self-instruction manual was developed and published covering the selected aspects of puberty. The title of the booklet is Managing Common Problems at Puberty - A Guide for Adolescent Girls".

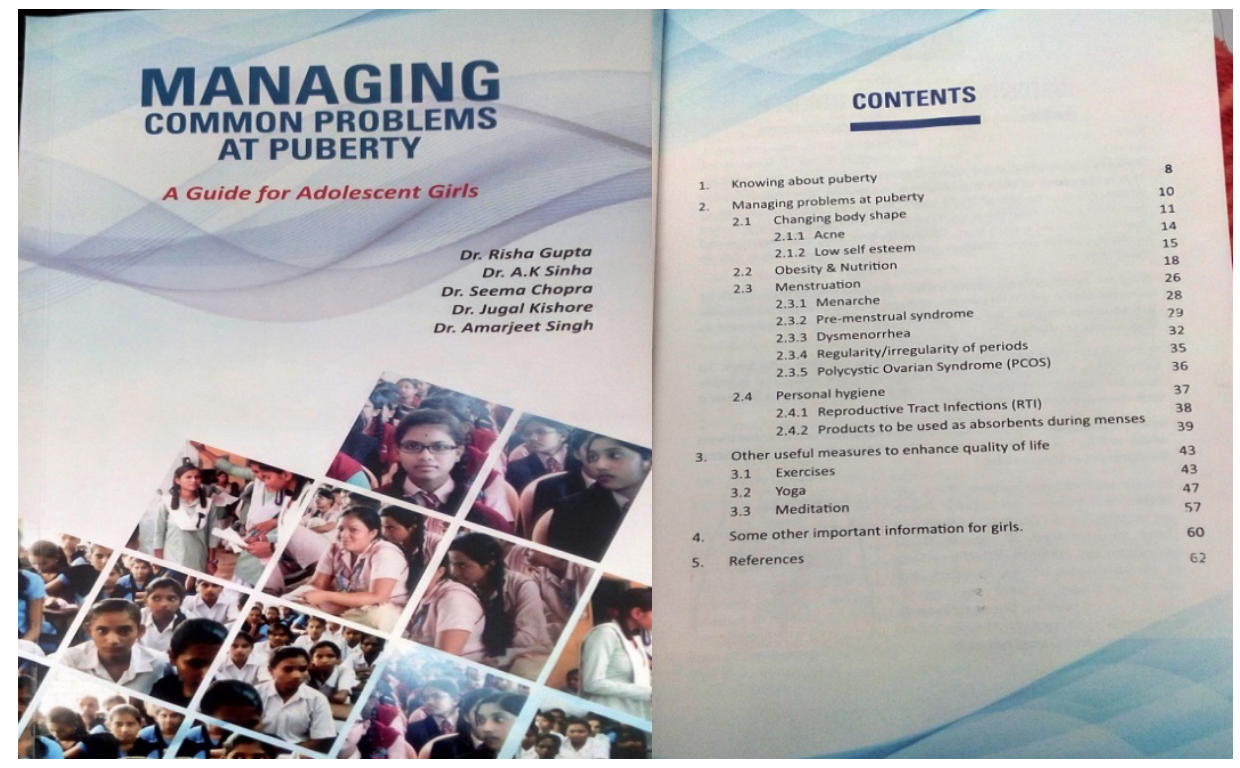

Figure 1\&2.Cover Page and Contents of the Self-instruction Manual

Face and content validity was sought from a panel of experts from public health, dermatology, gynecology, psychology, endocrinology, etc., and respondents with the help of a criteria rating tool. 
Table 3. Validation Results (Score $=0-10)$ of Information Booklet by the Respondents $(n=14)+\operatorname{Experts}(n=10)$

\begin{tabular}{|c|c|c|c|c|}
\hline \multirow{2}{*}{ Domains of the Booklet } & \multicolumn{2}{|c|}{ Respondents } & \multicolumn{2}{c|}{ Experts } \\
\cline { 2 - 5 } & Range & Mean \pm SD & Range & Mean \pm SD \\
\hline Matches client understanding level & $8-10$ & $8.93 \pm 0.73$ & $7-10$ & $8.64 \pm 1.01$ \\
\hline Technical content looks OK & $8-10$ & $8.64 \pm 0.84$ & $7-10$ & $8.79 \pm 0.89$ \\
\hline Has logical sequence of text & $7-10$ & $8.86 \pm 0.94$ & $7-10$ & $8.71 \pm 0.99$ \\
\hline Continuity of text is fine & $7-10$ & $8.71 \pm 1.14$ & $8-10$ & $8.93 \pm 0.73$ \\
\hline Language is understandable & $8-10$ & $9.14 \pm 0.77$ & $6-10$ & $8.86 \pm 1.10$ \\
\hline Do not have too much jargon in the terminology; too simple & $6-10$ & $8.57 \pm 1.45$ & $6-10$ & $8.71 \pm 1.20$ \\
\hline Diagrams/photos are simple to understand & $7-10$ & $8.79 \pm 1.12$ & $7-10$ & $8.79 \pm 1.05$ \\
\hline Font is appropriate & $7-10$ & $9.07 \pm 0.91$ & $8-10$ & $9.14 \pm 0.77$ \\
\hline Is handy (easy to carry for students) & $6-10$ & $9.07 \pm 1.14$ & $7-10$ & $8.86 \pm 1.17$ \\
\hline Is not loaded with unnecessary information & $7-10$ & $8.79 \pm 0.80$ & $6-10$ & $8.64 \pm 1.01$ \\
\hline Permits self-learning & $7-10$ & $8.79 \pm 0.97$ & $7-10$ & $8.93 \pm 0.91$ \\
\hline Readers will have some take home message & $6-10$ & $8.71 \pm 1.27$ & $8-10$ & $9.14 \pm 0.86$ \\
\hline Is useful with practical value & $7-10$ & $8.93 \pm 1.07$ & $8-10$ & $9.36 \pm 0.63$ \\
\hline Overall score & $\mathbf{8 - 1 0}$ & $\mathbf{9 . 5 7 \pm 0 . 6 4}$ & $\mathbf{8 - 1 0}$ & $\mathbf{9 . 1 4 \pm 0 . 7 7}$ \\
\hline
\end{tabular}

The content given in the booklet was highly appreciated by the respondents. They said:

- "Information given in the booklet is quite useful".

- $\quad$ "This is a very valuable book for the health \& hygiene education for girls. It also gives a very positive message to society".

- What the experts said about the booklet:

- "The information given in the booklet regarding menarche, health and hygiene should be made a part of syllabus. This will help all the girls in the age of puberty to handle themselves in a much better manner. This in turn will help them to take menstruation as a normal biological process and stop hating or grieving that period".

- "Adolescent girls generally have incorrect notions, which may lead to unsafe health practices. This booklet has complete information about managing common problems at puberty and related aspects. This also provides knowledge on physical, physiological and psychological changes during adolescence. So, this booklet is of immense practical value".

After incorporating all the suggestions, the booklet was published by Century Publications, New Delhi, and released. It was distributed in 16 schools of UT Chandigarh. The response was good. Teachers of the schools asked for some extra copies of the booklet as it covers the holistic concept of health and wellness among adolescent girls. They wish to themselves educate every girl regarding these aspects through the booklet. They also said they could arrange these booklets through library funds.

\section{Discussion}

Adolescence in girls is one of the most important phases of their lives. It involves physical, biological, psychological and emotional changes. They usually have many doubts and issues in their minds about such changes. All this often disturbs a girl and affects her quality of life. The major changes which a girl deals with at puberty are menstruation, changing body shape, appearance of pubic hair, body odor, weight fluctuations, etc.

But due to the conservative nature of our society, these issues remain unaddressed. They feel shy and hesitant to discuss these with anyone. This fosters a wrong notion among girls that menstruation is a dirty thing and that girls also get dirty with this.

In this context, Swami Vivekananda truly said "We can interfere only to the limit of giving education. Women must be put in a place to solve their problems in their own way. No one can or ought to do this for them. And our Indian women are capable of doing it as any in the world". In other words, women should be empowered. We should increase their access to appropriate information, thus enhancing their knowledge and creating opportunities to develop life skills.

In our study, we tried to resolve the puberty-related health problems among adolescent girls through imparting educational intervention packages.

The information booklet was prepared after assessing the information needs of the adolescent girls. It was introduced 
in the study population after validation. Face and content validity was sought from 10 experts and 14 respondents. The overall score given by experts ranged from 8 to 10 (with mean 9.14) and the respondents ranged from 8 to 10 (9.57). This shows according to them, this intervention booklet could be quite useful. One of the experts even remarked that considering the early onset of puberty, it could even be introduced at the $7^{\text {th }}$ standard.

Girls should ideally know the main underlying cause of puberty. Because if they do not know, they might think that something wrong has happened to them. In the present study, most ( $>80 \%$ ) girls already knew about hormones as the main underlying cause for puberty.

Our study showed that the major source of information for the girls was mother, followed by friends and sisters. The results of the study conducted by Thakre et al. ${ }^{3}$ showed only $36.95 \%$ of the participants were aware of menstruation before menarche and mothers were the first informants for more than $70 \%$ girls. This finding supports the need for involvement of mothers in health education programs.

There was much influence of advertisements of beauty products shown on television or other media channels. So, we can say that television can be used as a great media to communicate healthy practices to girls. Nemade et al. ${ }^{4}$ in their study recommended that advertisements should be made more informative and student-friendly so that they can be perceived well by adolescent school girls.

Very few girls marked uterus as the site of origin of blood during menstruation. Some girls marked ovary, and some marked stomach. This means they knew very less about the female anatomy and physiology. In a study conducted by Singh et al., ${ }^{5}$ among adolescent girls of Varanasi district (UP), $43.5 \%$ of the girls correctly told uterus as the organ from where the menstrual blood comes.

Almost all girls knew the correct method of disposing a pad. This could be because of the reason that girls were taught by their mothers at a very early stage about how to manage their periods.

Half of the girls (50\%) missed their periods after menarche once or more. But majority of them never did anything to manage this. Instead, they usually got disturbed and also faced difficulty in guessing the occurrence of periods every month. Actually, it is well known that at menarche, it takes a while for menses duration and gap to settle down. Most of the girls normally experience irregular periods. It may even take months or years to become regular. So, it is not a thing to get worried about. The only thing to do is to take appropriate diet and adopt a healthy lifestyle.

Many girls liked to drink ginger tea during menses. The probable reason could be they might get some sort of relief from pain and discomfort associated with menstruation. This fact is supported by another study by Gupta, ${ }^{6}$ where $25 \%$ girls reported ginger intake because it gave them a sense of relief. Rest of the majority would like to take other food stuffs like chocolates, ice-cream, junk food, etc. In the present study, almost all the girls used sanitary pads as the absorbent material whereas in the study by Thakre et al., ${ }^{3}$ majority of the rural girls were using cloth menstrual pads as the main absorbent material.

Dysmenorrhea, i.e., pain during menstruation is a very common thing for more than $90 \%$ girls as reported by the study conducted by Chaudhuri et al. ${ }^{7}$ However, very few seek treatment. The result of our study also showed that the majority of the girls tolerated their pain as such. The reason quoted by many of them was either the influence of mother/grandmother or shyness to discuss this issue with anyone. In a similar study by Gupta, ${ }^{6}$ only $13-14 \%$ participants ever consulted a physician for their pain. In our Indian society, this has become a trend that mothers usually told their daughters to tolerate the pain by saying "yeh to sabko hota hai, hume bhi hota hai, apne ap theek ho jayega".

Lack of knowledge, socio-cultural factors and ignorance are responsible for this low treatment-seeking behavior of the girls and women. Nearly one-third of the girls were using hot water bottle and quoted that they got enough relief by using it. The use of hot water bottle had been reported by some other studies also, such as study by Gupta, ${ }^{6}$ (reported by $37-53 \%$ participants), Aditi ${ }^{7}$ (37.33\% respondents), and Sharma ${ }^{8}$ (15.4\% participants) from PGIMER, Chandigarh. Thus, we can say that home remedies can be quite effective for the management of dysmenorrhea. Girls should know that dysmenorrhea is curable so that the wrong message does not disseminate to the next generation.

Physical activity and exercise can have a great impact on the manifestations of our body changes. The severity of many problems like dysmenorrhea, PCOD, etc., automatically lessens if we regularly do some exercise. In our study, only 33 girls reported practicing exercise daily like dancing, jogging, stretching, walking, etc., and they were doing it for nearly 30-40 minutes. This fact is supported by another study in Chandigarh and Mohali, where only $4.6 \%$ girls practiced exercise daily. Girls should know the importance of physical activity. It solves many of their problems, even excessive weight gain.

This shows that girls have a lot of information needs. They require appropriate education about all the aspects of puberty. This finding has been supported by another study by Gupta et al., ${ }^{2}$ in which the authors showed that there was a huge information gap among adolescent girls regarding puberty.

We had tried our best to incorporate all the necessary 
elements in the information booklet based on the information needs of the study population. The experts recommended certain changes in the booklet such as increase in font size, change of sequence of text in one or two sections and incorporation of more diagrams. We introduced the intervention to the study population having done all the above cited changes. The response came out to be quite good.

In this context, it will be quite pertinent to mention that the issue of reproductive health and hygiene of women, especially girls, has received considerable attention of the media and the movie makers, e.g., various advertisements and movies like Padman/Toilet - Ek Prem Katha. So our booklet and the research on this topic is a humble contribution to this noble cause.

\section{Conflict of Interest: None}

\section{References}

1. The Bangkok charter for health promotion in a globalized world. Health Promotion International. WHO 2007; 21(S1): 10-14.

2. Gupta R, Singh A. Level of understanding, information needs and practices of adolescent girls about selected puberty-related health and nutrition problems. Ind J Youth Adol Health 2017; 4(3): 34-39.

3. Thakre SB, Thakre SS, Reddy M et al. Menstrual hygiene: knowledge and practice among adolescent school girls of Saoner, Nagpur district. Journal of Clinical and
Diagnostic Research 2011 Oct; 5(5): 1027-33.

4. Nemade D, Anjenaya S, Gujar R. Impact of health education on knowledge and practices about menstruation among adolescent School girls of Kalamboli, Navi-Mumbai. Health and Population: Perspectives and Issues 2009; 32(4): 167-75.

5. Singh MM, Devi R, Gupta SS. Awareness and health seeking behaviour of rural adolescent school girls on menstrual and reproductive health problems. Indian Journal of Medical Sciences 1990; 53(10): 439-43.

6. Gupta R. A quasi experimental study to assess the effectiveness of active exercises and dietary ginger vs. active exercises on primary dysmenorrhea in adolescent girls of selected colleges of nursing, Chandigarh. M.Sc. thesis (unpublished). National Institute of Nursing Education. PGIMER, Chandigarh. 2013.

7. Chaudhuri A, Singh A, Dhaliwal L. A randomized control trial of exercise and hot water bottle in management of dysmenorrhea in school girls of Chandigarh. Indian Journal of Physiology and Pharmacology 2013; 57(2): 114-22.

8. Sharma E. An interventional study to assess the effectiveness of acupressure at SP6 on dysmenorrhea among B.Sc. Nursing students, NINE, PGIMER, Chandigarh, 2013-14. M.Sc. thesis (unpublished). National Institute of Nursing Education, PGIMER, Chandigarh. 2014.

Date of Submission: 2018-03-22 Date of Acceptance: 2018-04-28 